\title{
Prostatic cancer with metastasis to the testis - A case report
}

\author{
Chapagain $\mathrm{U}^{1}$, Neupane $\mathrm{S}^{1}$, Tuladhar $\mathrm{S}^{1}$, Pradhananga $\mathrm{S}^{1}$, Basnet RB ${ }^{1}$, Regmi $\mathrm{S}^{2}$ \\ ${ }^{1}$ Department of Pathology and Civil Service Hospital, Kathmandu, Nepal \\ ${ }^{2}$ Urology Department, Civil Service Hospital, Kathmandu, Nepal
}

\author{
Keywords: \\ Prostate adenocarcinoma; \\ testicular; \\ Metastasis; \\ PSA; \\ Immunohistochemistry;
}

\begin{abstract}
Metastatic carcinoma to the testis is very rare. The incidence of secondary testicular tumors ranges from 0.02 to $2.5 \%$ among autopsies in general. Despite the high incidence of prostatic adenocarcinoma and its ability for wide dissemination, metastatic cancer to the testis is a rare phenomenon of prostate carcinoma with only 80 cases reported in the literature. It is diagnosed in autopsies or incidentally, following therapeutic orchiectomies in more advanced stages of the disease.

Ours is the very first case of prostatic carcinoma metastasizing to the testis, being reported from our country. We are reporting this case because of the rarity of metastasis of prostatic carcinoma to testis and for stressing the need for keeping in mind the possibility of metastatic carcinoma also while dealing with testicular tumors. In our case, unilateral testicular metastasis was detected incidentally after bilateral orchiectomy for hormonal management of metastatic prostate carcinoma. The metastatic lesion was not identified in physical examination or in macroscopic dissection of the testis after surgery. Microscopy revealed an adenocarcinoma which, given the history of the patient and a positive immunohistochemical stain for PSA, was identified as metastatic prostatic adenocarcinoma.
\end{abstract}

\section{INTRODUCTION}

Prostate adenocarcinoma is the most frequently diagnosed neoplasm in men and its natural history is largely known. The most common metastatic sites are iliac lymph nodes, bones and lungs, then followed more rarely by bladder, liver, adrenal and brain. ${ }^{1}$ Metastatic carcinoma to the testis, excluding lymphomas and leukemias, is an extremely rare phenomenon. ${ }^{2}$ The majority of these cases are presented at autopsy in about $2.5 \%$ of men with malignant tumors or are incidentally detected during therapeutic orchiectomy for prostatic cancer. ${ }^{3}$ Of the metastatic lesions found, most are from prostate and lung cancer, and usually resemble

\section{Correspondence:}

Dr. Udita Chapagain, $M B B S, M D$

Department of pathology

Civil Service Hospital, Kathmandu, Nepal the primary tumor histologically. We describe a prostatic adenocarcinoma metastatic to testis and review the literature to show that rare testicular prostate cancer metastasis may be found incidentally if the testes are examined histologically. ${ }^{2}$

\section{CASE REPORT}

A 70-year-old gentleman presented to the department of urology at our hospital with complaints of urinary obstruction and irritation. Digital rectal examination showed an asymmetric prostate with indurated and fixed left lobe. Trucut biopsy was performed and prostatic acinar adenocarcinoma was detected (Gleason score $4+3=7$ ). Prostate-specific antigen (PSA) level was $67.5 \mathrm{ng} /$ $\mathrm{ml}$ at initial study that increased to $142.5 \mathrm{ng} / \mathrm{ml}$ on serial observation. Abdominopelvic CT scan was carried out and 


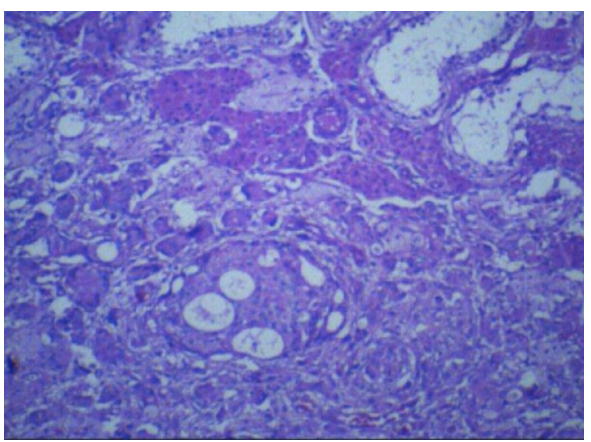

Figure 1: Cribriform and adenoid forms of metastatic adenocarcinoma to the testis with adjacent seminiferous tubules(HE stain, X100)

revealed enlarged periprostatic, retroperitoneal, preaortic, para-aortic, aortocaval, retroaortic, bilateral iliac, bilateral inguinal lymph nodes. Clinically, it was diagnosed as Metastatic carcinoma prostate. Bilateral orchiectomy was performed for hormonal management of metastatic prostate cancer. Our pathology department received bilateral orchiectomy specimen.

Right testis measured $52 \times 25 \times 17 \mathrm{~mm}$ and left testis measured $50 \times 20 \times 10 \mathrm{cms}$. External and cut surfaces had no visible focal lesions. Varying degrees of tubular atrophy was detected in microscopic examination of both testes. The metastatic lesion was in few small foci in the interstitium of the right testis and consisted of epithelial cells with cribriform and adenoid form with moderate to abundant vacuolated to granular cytoplasm, hyperchromatic nucleus and a prominent nucleolus. (fig.1) Surrounding desmoplastic reaction was also noted. We detected no intratubular spread. The metastatic lesion had similar differentiation as the primary lesion (Gleason score was $4+3=7$ in the metastatic lesion as well). Immunohistochemical stain for detection of PSA was positive.(fig.2)

\section{DISCUSSION}

Metastatic testicular tumors are unusual, with a total of 265 reported cases found in the literature. ${ }^{4}$ Pugh reported that $0.9 \%$ of 2739 testis tumors were metastatic. ${ }^{5}$ The most common primary sites of metastases to testis are prostate, lung, skin (malignant melanoma), colon and kidney in order of decreasing frequency, collectively comprising $72 \%$ of all reported cases. ${ }^{4}$

In Mayo Clinic experience, of the 550 patients with testicular tumors, $20 \mathrm{had}$ a tumor metastatic to the testis and the site of the primary tumor was the prostate in 12 patients ( $60 \%$ of the metastatic tumors). ${ }^{6}$

Most of the patients with metastatic tumors tend to be in the sixth or seventh decade of life, older than the patients

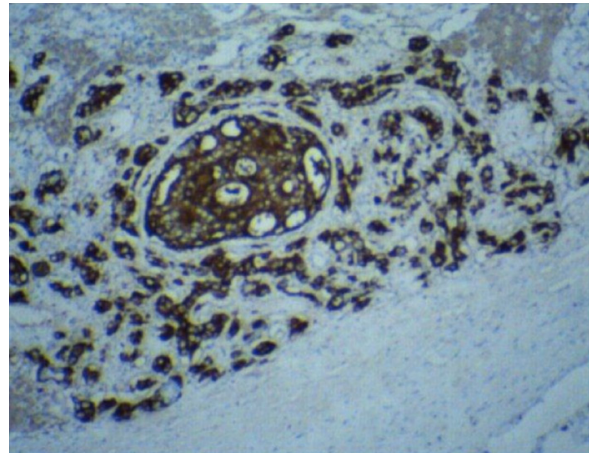

Figure 2: Cytoplasmic positivity for PSA in metastatic epithelial cells (IHC stain, X100)

with primary germ cell neoplasm. Metastasis was bilateral in a small proportion of cases. ${ }^{7}$ The majority of reported cases are detected either as incidental findings in surgical specimens following therapeutic orchiectomy or upon excision of hydrocele sacs or at autopsy. Only $20 \%$ of the reported cases are clinically apparent testicular metastases. $^{4}$

Prostatic cancer usually spreads to the testis via lymphatic or venous routes or through direct extension via vas deferens, and seldom invades the interstitium through the seminiferous tubules. ${ }^{8}$ We did not find any lesions in the epididymis and rete testis in this patient. Hence we ruled out a direct extension of the tumor via vas deferens in our case. The tumor cells were more likely spread by the lymphatic or venous route but we could not determine which. The metastatic lesion in our patient was unilateral and detected incidentally. It was impossible to identify the metastatic lesion in a physical examination or in macroscopic dissection of the testis. The malignant epithelial cells were arranged in glandular form, suggesting that this was a metastatic lesion from an adenocarcinoma. The presence of a history of prostatic adenocarcinoma helped us to recognize this as a metastatic prostatic adenocarcinoma. Positive immunohistochemical stain for PSA confirmed this diagnosis.

Interestingly, the differentiation of cells in the metastatic lesion was similar to the primary tumor (Gleason score $4+3=7$ ). In conclusion, all testes removed for early or delayed hormonal therapy of prostate cancer should be sent for routine histologic examination. Whole testicular tissue should be prepared and examined microscopically because macroscopic dissection of the testis may not show the metastatic lesion. Some patients whose disease is not clinically metastatic, and for whom radical surgery is not suitable because of their age or poor performance status, may be treated with early hormone ablation therapy (orchiectomy + antiandrogen therapy). In such patients any incidental testicular metastasis provides the real 
pathologic stage although the treatment does not require significant change. $^{2}$

\section{REFERENCES}

1. Carlos MN Jesus, Jose Goldberg, Joao L.V. Camargo. Single testicular metastasis mimicking primary testicular neoplasm: a rare manifestation of prostate cancer. Int Braz J Urol. 2005;31:546. Crossref

2. Kadir Baykal, Sukru Yildirim, Haluk Inal, et al : Metastasis of prostate adenocarcinoma to testis. Int J Urol. 1997;4:104-5. Crossref

3. Lieng-Yi Lu, Junne-Yih Kuo, Alex T.L. Lin et al: Metastatic tumors involving testis. J Urol R.O.C. 2000;11:12-7.

4. Petersen RO. Testis. In: Petersen RO (ed) Urologic pathology. Philadelphia: JB Lippincott, 1992. pp. 429-525.
5. Pugh BC. Testicular tumors-introduction. In: Pugh BC(ed) Pathology of the testis. Oxford: Blackwell Scientific Publications, $1976 ; 139 p$

6. Patel SR, Richardson RL, Kvols L. Metastatic cancer to the testis. A report of 20 cases and review of the literature.J Urol 1989;142:10035. Crossref

7. Richie JP. Neoplasm of the testis. In: Walsh PC, Retik AB, Stamey TA, Vaughan ED (eds) Campbells urology. Philadelphia: WB Saunders, 1992. pp1222-63.

8. Singh M, Samaratunga C, Wright C, Guaydalini I. Prostatic carcinoma metastasizing to the testis-an unusual pattern of spread. $\mathrm{Br}$ J Urol 1995;75:803-4. Crossref 